\title{
Postmenopausal Women and Osteoporosis
}

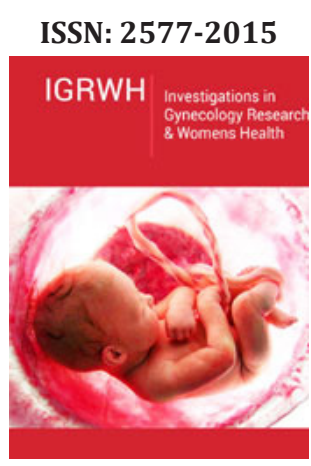

*Corresponding author: Shivani Garg, Department of Obstetrics and Gynecology, India

Submission: 傮 October 01, 2020

Published: 侐 November 05, 2020

Volume 3 - Issue 5

How to cite this article: Nishi Garg, Sonal Garg, Shivani Garg. Postmenopausal Women and Osteoporosis. Invest Gynecol Res Women's Health. 3(5). IGRWH. 000571. 2020.

DOI: 10.31031/IGRWH.2020.03.000571

Copyright@ Shivani Garg, This article is distributed under the terms of the Creative Commons Attribution 4.0 International License, which permits unrestricted use and redistribution provided that the original author and source are credited.

\author{
Nishi Garg, Sonal Garg and Shivani Garg* \\ Department of Obstetrics and Gynecology, India
}

\section{Introduction}

Postmenopausal osteoporosis is a silent disease with not much of symptoms until fractures occur. It is characterized by low bone mineral density (BMD) and changes in bone microarchitecture that reduces bone strength and there is increase in risk of fractures [1]. After menopause, estrogen deficiency is the major contributing factor. Because of this there is an increase in RANK-ligand (RANKL) and a decrease in osteoprotegerin (OPG) secretion from osteoblasts. This imbalance induces fast bone loss, and thus there is increase in risk of fractures. WHO has identified osteoporosis as a major public health concern [2]. Osteoporosis is widely recognized as an important public health problem because of the significant morbidity, mortality and costs associated with its complications-namely fractures of the hip, spine, forearm and other skeletal sites [3]. The incidence of fragility fractures is highest among elderly white women, with one in every two women suffering an osteoporosis related fracture in their lifetime [4]. Each year in the UK an estimated 260000 osteoporotic fractures occur among women aged 50 years and over, including over 70000 cases of hip fracture $[5,6]$. For the Indian population, the exact figures on the prevalence of osteoporosis are not available, but the estimation is that more than 61 million Indians have osteoporosis with women accounting for $61 \%$ of them $[7,8]$.

A study was done to determine the prevalence of osteoporosis in Indian women and reported that 106 of the studied 200 patients had low BMD (osteopenia and osteoporosis) [9]. According to WHO criteria, osteoporosis is defined as the T-score of less or equal to 2.5 and osteopenia as the T-score between 1.0 and 2.5. The femoral neck and lumbar spine are recommended as the anatomic region of interest [10]. BMD decreases with age; thus, primary osteoporosis mainly occurs in women 10-15 years after menopause. Although for many years there was awareness of the morbidity and mortality associated with fragility fractures, but real progress only came with the ability to diagnose osteoporosis with BMD machines before the occurrence of fractures. Measurements of bone mineral density (BMD) played a crucial role. Until the mid-1980s bone density measurements were used mainly for research, and it was only with the introduction of dual-energy x ray absorptiometry (DEXA) scanners in 1987 that they entered routine clinical practice [11]. The lumbar spine (lower back) and the hip are the skeletal sites usually examined by bone densitometry.

The procedure can be performed by many methods:

a) Dual energy X-ray absorptiometry (DEXA).

b) Peripheral dual energy X-ray absorptiometry (P-DEXA).

c) Quantitative Computed Tomography (QCT).

d) Ultrasound.

e) Dual photon absorptiometry (DPA).

\section{Treatment}

The treatment of osteoporosis is to prevent fractures and involves pharmacological and non-pharmacological approaches. 


\section{Non-Pharmacological Treatment}

\section{Lifestyle modifications}

Peak bone mass is achieved during the third decade of life, and it is mainly determined by genetic influence and modified by lifestyle and health status. The activities like walking, strengthening exercises, Yoga are helpful in menopause. Patients should be encouraged to stop smoking and reduce excessive alcohol and caffeine intake [12]. Women in this age group should be advised regarding fall prevention in their homes. They should be advised to take care of symptoms like dizziness, postural hypotension, poor vision, and inadequate footwear [12]. They should be advised regarding physical exercise programs. This maintains and / or increase spine and hip bone mineral density, as well as decrease the frequency of falls among osteoporotic and osteopenic patients [13].

\section{Calcium \& vitamin D}

The recommended daily calcium intake for postmenopausal women is $1,200 \mathrm{mg}$, with an upper limit of $2,000 \mathrm{mg}$ [14] If diet is not sufficient to provide calcium, then calcium supplements have to be considered. The source of vitamin D in diet is very limited and it is mainly dependent on the skin for formation after UV radiation. Lower concentrations of vitamin D are associated with elevated levels of PTH and, consequently, high resorption rate, and high risk of fractures. Daily dietary allowance of $600 \mathrm{IU}$ is recommended for 51-70 years old women, and 800 IU for those older than 70 years old, with an upper limit of 4,000 IU [14]. However, the Endocrine Society guideline recommends 1,500-2,000 IU daily, with an upper limit of 10,000 IU [15]. Vitamin D status is best assessed by measuring levels of 25(OH)D. In adults with very low 25(OH)D levels (under $20 \mathrm{ng} / \mathrm{mL}$ ), a 7,000IU daily or 50,000 units weekly, for 6 to 8 weeks or longer, may be necessary [15]. In our experience, doses higher than 1,000 IU/day of vitamin D3 are necessary to maintain 25-hydroxyvitamin D [25(OH)D] within normal range (>30ng/mL) in osteoporotic patients.

\section{Antidepressants}

The selective serotonin reuptake inhibitors (SSRI), paroxetine [16] and venlafaxine, may reduce hot flushes and also to lift the mood swings.

\section{Phytoestrogens}

Phytoestrogens improve symptoms of acute climacteric syndrome [17]. However, there are not many studies proving their efficiency. Phytoestrogens are nonsteroid plant-derived compounds able to produce an estrogenic effect. They are usually divided into three groups:
1) Isoflavones (daidzein, genistein, biochanin formononetin, glycitein)
2) lignans (secoiso lariciresinol-diglucosid, matairesinol)
3) Coumestans.

\section{Hormone Replacement Therapy (HRT)}

\{Conjugated Equine Estrogen, Estradiol valerate, Transdermal Estrogen cream and patches\}

There is lots of evidence that shows that bone loss starts 2-3 years prior to the menopause, and it is accelerated with menopause due to lack of estrogen. This process continues for up to 5-10 years. Estrogen deficiency is associated with increase in bone marrow levels of a number of pro-resorptive cytokines, including TNF- $\alpha$, IL-1 $\alpha$, and others [18]. This suppression of osteoclast activity by estrogen replacement therapy has been used effectively for decades. Nowadays, the primary indication of HRT is the treatment of moderate and severe menopausal symptoms (i.e., vasomotor symptoms, vaginal atrophy). With long-term therapy there is an increased risk of adverse outcomes such as stroke and venous thromboembolic events. Women receiving estrogen and progestogen showed a small but significant increase in breast cancer in the Women's Health Initiative study. However, using estrogen alone in hysterectomized women reduced the incidence of invasive breast cancer compared with placebo ( $p=0.06$, not significant) [19]. There are various preparations available. The side effects are proportionate to the dose used. We have to select an agent oral vs transdermal depending on women's need and symptoms.

\section{Tibolone}

Tibolone is a progestogen with selective tissue estrogenic activity. It exhibits weak estrogenic, progestogenic, and androgenic activity. It suppresses vasomotor problems and improves mood and libido at the recommended dose of $2.5 \mathrm{mg}$ /day. It improves vaginal atrophy, but it does not affect the endometrium. It has a protective effect on bone mass, even in a dose of $1.25 \mathrm{mg} /$ day. It reduces proliferation of breast epithelial cells, does not increase mammographic density $[20,21]$. It may cause weight gain so to be used judiciously in obese women.

\section{Selective Estrogen Receptor Modulators (SERMS)}

SERMs bind to the estrogen receptor (ER) with high affinity for bone and cardiovascular system and antagonist for breast and in some cases endometrium. Raloxifene is approved for the prevention and treatment of postmenopausal osteoporosis $(60 \mathrm{mg} /$ day). The same response was observed in improvement of BMD [22]. The MORE (Multiple Outcomes of Raloxifene Evaluation) study demonstrated a $30 \%$ reduction of vertebral fracture risk (RR, $0.7 ; 95 \% \mathrm{CI}, 0.5-0.8$ ), but not in non-vertebral fractures during a follow-up of 3 years [23]. Raloxifene also reduced the risk of ERpositive-invasive breast cancer (RR, 0.24; 95\% CI, 0.15-0.40) and endometrial cancer (RR, 0.62; 95\% CI, 0.35-1.08) [24,25]. The RUTH A, (Raloxifene Use for The Heart) study, involving postmenopausal women with high risk of cardiovascular disease for 5 years, showed an increased risk of fatal stroke (HR, 1.49; 95\% CI, 1.00-2.24) and venous thromboembolism (HR, 1.44; 95\% CI, 1.06-1.95) [26]. It is well tolerated, with few cases experiencing hot flushes and leg 
cramps. So, it is not recommended to symptomatic postmenopausal women [23]. A 5-year study of bazedoxifene (20 or 40mg) showed a reduction of 35 and $40 \%$ of the risk of vertebral fractures, respectively. There was no stimulatory effect on the endometrium, but it was associated with increased vasomotor symptoms, leg cramps, and venous thromboembolism [27].

\section{Bisphosphonates}

Bisphosphonates are the most used anti-resorptive agents in the treatment of osteoporosis. They strongly bind to the mineralized tissue, especially in the active remodeling sites. They are removed from bone by osteoclasts during resorption and are not metabolized for excretion. Therefore, they can be rebound by the mineralized tissue again. The most potent molecules in Bisphosphonates have a nitrogen-containing chain, such as alendronate, risedronate, ibandronate, and zoledronate. Skeleton-binding affinity increases in this rank order: risedronate, ibandronate, alendronate, and zoledronate [28]. Alendronate can be given orally once a week (70mg), ibandronate once a month (150mg), and Risedronate once a week or once a month (35mg and $150 \mathrm{mg}$, respectively). Oral bisphosphonates are poorly absorbed (less than 1\%), and this has to be given with plain water only in the morning and in fasting state. After taking this tablet one has to be upright and not to lie down in bed as it causes lot of gastroesophageal reflux $[28,29]$. Ibandronate can also be given intravenously (IV) every 3 months ( $3 \mathrm{mg}$ ), and zoledronate once a year (5mg IV). Alendronate was the first bisphosphonate approved by the FDA for the prevention and treatment of osteoporosis. The once-weekly administration $(70 \mathrm{mg})$ improved the use and tolerability with the same or better efficacy than the daily therapy (10mg) [30]. The ideal duration of treatment with bisphosphonates is uncertain at this time. There is considerable evidence showing that anti-resorptive agents are effective in reducing fracture risk, and that they are well tolerated for over 3 to 5 years. There is a concern that long-term treatment may inhibit repair of microdamage, because of excessive mineralization, and may cause an increase in microcracks.

\section{Calcitonin}

A dose of $200 \mathrm{IU}$ of salmon calcitonin nasal spray significantly reduced the risk of new vertebral fractures.The side effects like occasional rhinitis, headache, flushing, nausea and diarrhoea have been reported more commonly with subcutaneous dose than with intranasal calcitonin.

\section{Denosumab}

Denosumab is a human monoclonal antibody is administered as 60-mg subcutaneous injection every 6 months. Its clearance occurs by means of the reticuloendothelial system and not by renal excretion. Therefore, denosumab can be given to patients with renal impairment.

\section{Teriparatide}

Intermittent administration of low-dose PTH enhances osteoblast activity and bone formation. It is administered as a 20 -mcg subcutaneous daily injection. There was a $65 \%$ and $54 \%$ reduction in fracture risk in vertebral and non-vertebral fractures. The use of teriparatide is limited to severe osteoporosis because of the high cost of the treatment.

\section{Strontium ranelate}

Strontium ranelate contains two atoms of strontium. It has a dual action, increasing bone formation and decreasing resorption, but its exact mechanism of action is still unclear. Long-term treatment with strontium ranelate was safe and associated with a sustained increase on BMD and in the anti-fracture efficacy over 10 years [31]. A new statement of European Medicines Agency (EMA) showed that use of strontium ranelate may cause an increased risk of cardiovascular disease. This should only be used to treat severe osteoporosis in postmenopausal women and men.

\section{New Osteoporosis Targets and New Mechanisms of Action}

\section{Cathepsin K inhibitors-Odanacatib}

Odanacatib (ODN) is a specific inhibitor of Cathepsin $\mathrm{K}$ is a lisosomal enzyme produced by the osteoclast. Treatment with ODN for up to 5 years was generally well-tolerated [32].

\section{Antiesclerostin antibodies}

Sclerostin is a protein produced almost exclusively by osteocytes and its function is to prevent the Wnt signaling in osteoblasts. The activation of Wnt pathway in the cell membrane of osteoblasts strongly induces bone formation. New monoclonal antibodies against sclerostin have been developed and are new promising therapeutic goal for osteoporosis.

\section{Discussion}

Menopause is a natural physiological phenomenon resulting from primary ovarian failure. Ovarian function declines with age. The onset of menopause manifests with decreasing production of estradiol, as well as increasing levels of follicle-stimulating hormone (FSH). According to WHO criteria, osteoporosis is defined as the T-score of less or equal to 2.5 and osteopenia as the T-score between 1.0 and 2.5. The femoral neck and lumbar spine are recommended as the anatomic region of interest for Bone Mineral Density [33]. We should start the treatment early to prevent the complications. Menopause Hormone Therapy (MHT) has long been known to significantly increase BMD.

After one year the MHT group showed an average increase of bone mineral density at the lumbar spine of $5.4 \%$, and the forearm and femoral neck were also increased by $3.0 \%$ and $2.5 \%$ respectively. After two years of treatment, the percentage change in favour of MHT increased by about $1.5 \%$ at all sites with an increase by $6.8 \%, 4.5 \%$, and $4.1 \%$ at the lumbar spine, forearm, and femoral neck, respectively [34,35]. Besides Hormonal therapy, many other therapies including bisphosphonates, selected estrogen receptor modulators (SERMS), recombinant human parathyroid hormone, and denosumab are also effective. Calcium and vitamin D should be taken as basic nutritional supplements. Also, management includes lifestyle changes, regular exercise and strategies for prevention of 
falls [36]. Osteoporosis is a very common clinical situation, and it is expected that incidence will rise in the next decades due to the worldwide aging of the population. Bone loss and fractures follow the decrease in estrogen levels in the postmenopausal period, which increases osteoclast activity and, subsequently, bone resorption. The adequate intake of calcium and vitamin D are helpful before the start of osteoporosis treatment with specific drugs, as well as physical activity should be encouraged and prevention of falls to be looked into. Several drugs are already available with proven efficacy against fractures and excellent safety profiles. The challenge today is to improve the detection of osteoporosis and convince healthcare professionals to refer at-risk patients for treatment.

\section{References}

1. North American Menopause Society (2006) Management of osteoporosis in postmenopausal women: 2006 position statement of The North American Menopause Society. Menopause 13(3): 340-367.

2. Kanis JA (1994) Assessment of fracture risk and its applications to screening for postmenopausal osteoporosis: synopsis of a WHO report. WHO Study Group. Osteoporosis Int 4(6): 368-381.

3. Cummings SR, Melton LJ (2002) Epidemiology and outcomes of osteoporotic fractures. Lancet 359(9319): 1761-1767.

4. Kanis J A, Black D, Cooper C, Dargent P, Hughes BD, et al. (2002) A new approach to the development of assessment guidelines for osteoporosis. Osteoporos Int 13(7): 527-536.

5. Johansen A, Evans R J, Stone MD, Richmond PW, Lo SV, et al. (1997) Fracture incidence in England and wales: a study based on the population of Cardiff. Injury 28(9-10): 655-660.

6. Johansen A, Stone M (2000) The cost of treating osteoporotic fractures in the United Kingdom female population. Osteoporos Int 11(6): 551552.

7. Joshi VR, Mangat G, Balakrishnan C, Mittal G (1998) Osteoporosisapproach in Indian scenario. J Assoc Physicians India 46(11): 965-967.

8. Rao H, Rao N, Sharma LR (2003) A clinical study of bone mineral density using heel ultra-densitometer in Southern Maharashtra. Indian J Orthop 37: 9 .

9. Aggarwal N, Raveendran A, Khandelwal N, Sen RK, Thakur JS, et al. (2011) Prevalence and related risk factors of osteoporosis in peri-and postmenopausal Indian women. J Midlife Health 2(2): 81-85.

10. Kanis JA, Melton LJ, Christiansen C, Johnston CC, Khaltaev N (1994) The diagnosis of osteoporosis. J Bone Miner Res 9(8): 1137-1141.

11. Genant HK, Engelke K, Fuerst T, Glüer CC, Grampp S, et al. (1996) Noninvasive assessment of bone mineral and structure: state of the art. J Bone Miner Res 11(6): 707-730.

12. Daroszewska A (2012) Prevention and treatment of osteoporosis in women: an update. Obstet Gynaecol Reprod Med 22(6): 162-169.

13. Galvão APRL, Castro ML (2010) Physical approach for prevention and treatment of osteoporosis. Arq Bras Endocrinol Metab 54(2): 171-178.

14. Ross AC, Taylor CL, Yaktine AL, Valle HBD (2011) Dietary reference intakes for calcium and vitamin D. The National Academies Press, Washington, USA.

15. Holick MF, Binkley NC, Ferrari HAB, Gordon CM, Hanley DA, et al. (2011) Evaluation, treatment, and prevention of vitamin D deficiency: An Endocrine Society clinical practice guideline. J Clin Endocrinol Metab 96(7): 1911-1930.

16. Rahimzadeh P, Imani F, Nafissi N, Ebrahimi B, Faiz SHR (2018) Comparison of the effects of stellate ganglion block and paroxetine on hot flashes and sleep disturbance in breast cancer survivors. Cancer Manag Res 10: 4831-4837.

17. Lethaby A, Marjoribanks J, Kronenberg F, Roberts H, Eden J, et al. (2013) Phytoestrogens for menopausal vasomotor symptoms. Cochrane Database Syst Rev 12: CD001395.

18. Khosla S (2010) Update on estrogens and the skeleton. J Clin Endocrinol Metab 95(8): 3569-3577.

19. Anderson GL, Limacher M, Assaf AR, Bassford T, Beresford SA, et al. (2004) Effects of conjugated equine estrogen in postmenopausal women with hysterectomy: The women's health initiative randomized controlled trial. JAMA 291(14): 1701-1712.

20. Bruce D, Robinson J, Williams S, Reddy M, Fentiman I, et al. (2004) Longterm effects of tibolone on mammographic density. Fertil Steril 82(5): 1343-1347.

21. Yenen MC, Dede M, Goktolga U, Kuçuk T, Pabuçcu R (2003) Hormone replacement therapy in postmenopausal women with benign fibrocystic mastopathy. Climacteric 6(2): 146-150.

22. Sambrook PN, Geusens P, Ribot C, Solimano JA, Barriendos JF, et al. (2004) Alendronate produces greater effects than raloxifene on bone density and bone turnover in postmenopausal women with low bone density: results of EFFECT (Efficacy of FOSAMAX versus EVISTA Comparison Trial) International. J Intern Med 255(4): 503-511.

23. Ettinger B, Black DM, Mitlak BH, Knickerbocker RK, Nickelsen T, et al. (1999) Reduction of vertebral fracture risk in postmenopausal women with osteoporosis treated with raloxifene: results from a 3-year randomized clinical trial. Multiple Outcomes of Raloxifene Evaluation (MORE) Investigators. JAMA 282(7): 637-645.

24. Siris ES, Harris ST, Eastell R, Zanchetta JR, Goemaere S, et al. (2005) Skeletal effects of raloxifene after 8 years: results from the continuing outcomes relevant to Evista (CORE) study. J Bone Miner Res 20(9): 1514-1524.

25. Vogel VG, Costantino JP, Wickerham DL, Cronin WM, Cecchini RS, et al. (2006) Effects of tamoxifen vs raloxifene on the risk of developing invasive breast cancer and other disease outcomes: the NSABP Study of Tamoxifen and Raloxifene (STAR) P-2 trial. JAMA 295(23): 2727-2741.

26. Connor EB, Mosca L, Collins P, Geiger MJ, Grady D, et al. (2006) Effects of raloxifene on cardiovascular events and breast cancer in postmenopausal women. N Engl J Med 355(2): 125-137.

27. Silverman SL, Chines AA, Kendler DL, Kung AW, Teglbjærg CS, et al. (2012) Sustained efficacy and safety of bazedoxifene in preventing fractures in postmenopausal women with osteoporosis: results of a 5-year, randomized, placebo-controlled study. Osteoporos Int 23(1): 351-363.

28. Watts NB, Diab DL (2010) Long-term use of bisphosphonates in osteoporosis. J Clin Endocrinol Metab 95(4): 1555-1565.

29. Fleisch H (1998) Bisphosphonates: mechanisms of action. Endocr Rev 19(1): 80-100.

30. Schnitzer T, Bone HG, Crepaldi G, Adami S, Clung M, et al. (2000) Therapeutic equivalence of alendronate $70 \mathrm{mg}$ once weekly and alendronate $10 \mathrm{mg}$ daily in the treatment of osteoporosis. Alendronate once-weekly study group. Aging (Milano) 12(1): 1-12.

31. Reginster JY, Kaufman JM, Goemaere S, Devogelaer JP, Benhamou CL, et al. (2012) Maintenance of antifracture efficacy over 10 years with strontium ranelate in postmenopausal osteoporosis. Osteoporos Int 23(3): 1115-1122.

32. Langdahl B, Binkley N, Bone H, Gilchrist N, Resch H, et al. (2012) Odanacatib in the treatment of postmenopausal women with low bone mineral density: five years of continued therapy in a phase 2 study. J Bone Miner Res 27(11): 2251-2258. 
33. Kanis JA, Melton LJ, Christiansen C, Johnston CC, Khaltaev N (1994) The diagnosis of osteoporosis. J Bone Miner Res 9(8): 1137-1141.

34. Lewiecki EM (2008) Prevention and treatment of postmenopausal osteoporosis. Obstet Gynecol Clin N Am 35(2): 301-315.

35. Wells G, Tugwell P, Shea B, Guyatt G, Peterson J, et al. (2002) V metaanalysis of the efficacy of hormone replacement therapy in treating and preventing osteoporosis in postmenopausal women. Endocr Rev 23(4): 529-539.

36. Cole Z, Dennison E, Cooper C (2008) Update on the treatment of postmenopausal osteoporosis. Br Med Bull 86: 129-143.

For possible submissions Click below:

Submit Article 